\title{
Laparoscopic transperitoneal lateral adrenalectomy for malignant and potentially malignant adrenal tumours
}

\author{
Michał Pędziwiatr ${ }^{1 *}$, Mateusz Wierdak², Michał Natkaniec ${ }^{1}$, Maciej Matłok' ${ }^{1}$ Magdalena Białas ${ }^{3}$, Piotr Major ${ }^{1}$,
} Piotr Budzyński ${ }^{1}$, Alicja Hubalewska-Dydejczyk ${ }^{4}$ and Andrzej Budzyński ${ }^{1}$

\begin{abstract}
Background: Laparoscopic adrenalectomy is still controversial in cases where malignancy is suspected. However, many proponents of this technique argue that in the hands of an experienced surgeon, laparoscopy can be safely performed. The aim of this study is to present our own experience with the application of laparoscopic surgery for the treatment of malignant and potentially malignant adrenal tumours.

Methods: Our analysis included 52 patients who underwent laparoscopic adrenalectomy in 2003-2014 due to a malignant or potentially malignant adrenal tumour. Inclusion criteria were primary adrenal malignancy, adrenal metastasis or pheochromocytoma with a PASS score greater than 6 . We analyzed the conversion rate, intra- and postoperative complications, intraoperative blood loss and R0 resection rate. Survival was estimated using the Kaplan-Meier method.

Results: Conversion was necessary in 5 (9.7\%) cases. Complications occurred in a total of 6 patients (11.5\%). R0 resection was achieved in 41 (78.8\%) patients and R1 resection in 9 (17.3\%) patients. In 2 (3.9 \%) cases R2 resection was performed. The mean follow-up time was 32.9 months. Survival depended on the type of tumour and was comparable with survival after open adrenalectomy presented in other studies.

Conclusions: We consider that laparoscopic surgery for adrenal malignancy can be an equal alternative to open surgery and in the hand of an experienced surgeon it guarantees the possibility of noninferiority. Additionally, starting a procedure with laparoscopy allows for minimally invasive evaluation of peritoneal cavity. The key element in surgery for any malignancy is not the surgical access itself but the proper technique.
\end{abstract}

Keywords: Adrenocortical cancer, Pheochromocytoma, Adrenal metastasis, Laparoscopic adrenalectomy

\section{Background}

Laparoscopic adrenalectomy is currently the gold standard for the surgical treatment of adrenal pathology [1, 2]. Initially, laparoscopy was only applied in the surgery of small adrenal tumours, the character of which indicated a benign lesion. Indications for laparoscopy have gradually broadened since it has been established that practically any tumour, including very large ones, can be successfully removed with this technique. It has obviously typical advantages for minimally invasive surgery: a

\footnotetext{
* Correspondence: michal.pedziwiatr@uj.edu.pl

'2nd Department of General Surgery, Jagiellonian University, Kopernika 21, 31-501 Kraków, Poland

Full list of author information is available at the end of the article
}

lower complication rate, less postoperative pain, faster recovery, a shorter length of hospital stay and a better cosmetic effect $[3,4,1,5]$. However, its use is still controversial in cases where malignancy is suspected. One of the concerns is that maintaining the proper oncological technique may be more difficult in comparison to open access, and thus there would be a higher risk of tumour capsule injury, which leads to intraoperative dissemination of cancer cells [6]. However, proponents of minimally invasive techniques argue that in the hands of an experienced surgeon, laparoscopy can be safely performed while preserving the principles of oncologic surgery, with results similar to those of open access [7]. The aim of this study is to present our own 
experience with the application of laparoscopic surgery in the treatment of malignant and potentially malignant adrenal tumours.

\section{Methods}

Our analysis included patients who underwent laparoscopic adrenalectomy at our centre in the years 20032014 due to a malignant or potentially malignant adrenal tumour. The inclusion criterion was a postoperative pathological diagnosis confirming the character of the lesion: primary malignant tumour of the adrenal gland, pheochromocytoma with a high risk of postoperative malignant course or isolated adrenal metastasis after radical treatment of a primary lesion. We excluded from the study patients who were submitted to open surgery or patients with an inoperable tumour with distant metastases. Preoperative staging in all cases was comprised of computed tomography (CT), magnetic resonance imaging (MRI) or in selected cases a positron emission tomography (PET) scan. The criteria for potential malignancy in imaging studies included: invasion into adjacent organs or vessels, local or distant lymphadenopathy, increased and heterogeneous signal intensity on CT and on T2-weighted MRI, increased fludeoxyglucose uptake on PET and growth over time.

Prior to surgery a routine panel of laboratory tests were carried out to establish the hormonal activity of the tumour. The evaluation included plasma cortisol, urinary free cortisol, ACTH, DHEAS, 17-OH-progesterone, testosterone, plasma renin activity as well as aldosterone, urinary aldosterone, catecholamines and vanillylmandelic acid excretion. In the case of suspected pheochromocytoma, patients were preoperatively treated with alphablockers (doxazosin $20 \mathrm{mg} /$ day) (additional beta-blockers in case of co-existing tachycardia) and intravenous volume expansion with crystalloids and colloids $(2000 \mathrm{ml} /$ day starting on the day before surgery).

We performed laparoscopy using the transperitoneal lateral approach. The same laparoscopic surgeon (AB) with extensive expertise in adrenal surgery (more than 370 laparoscopic adrenalectomies) performed all laparoscopic transperitoneal lateral adrenalectomies. The first attempt to use the laparoscopic approach in case of suspected malignancy was after completion of his learning curve (50 laparoscopic adrenalectomies). The principle during surgery was to avoid direct manipulating or applying pressure to the tumour to prevent perforation of the tumour capsule, or, in the case of pheochromocytomas, secretion of catecholamines. Any suspicion of damage to the tumour capsule was considered an indication for conversion. The adrenal gland with the tumour was resected with a margin of surrounding tissue and removed in a plastic laparoscopic bag. After surgery, patients were submitted to adjuvant therapy according to their primary oncological diagnosis. All the patients were subject to regular follow-up, which included clinical examination and imaging tests.

\section{Definitions}

Primary tumours were defined as lesions originating in the adrenal gland. The potential risk of malignancy of the pheochromocytomas was evaluated with the Pheochromocytoma of Adrenal Gland Scaled Score (PASS); in postoperative pathological examination pheochromocytomas with a PASS score of 6 or higher were defined as potentially malignant [8]. Metastasis was defined as an adrenal tumour, discovered during follow-up diagnostic imaging, in patients with history of cancer in a different location, with a pathological diagnosis convergent with that of the later removed adrenal tumour.

The surgical procedure was described as R0 resection (macroscopically and microscopically radical), R1 resection (macroscopically radical, microscopically not radical - if the operative margin was smaller than $3 \mathrm{~mm}$ or when the pathologist was unable to definitively evaluate the radicality of the procedure in the report) or R2 resection (a procedure macroscopically and microscopically not radical or an intraoperative perforation of the tumour capsule).

The analysed measures were: conversion rate, intra- and postoperative complications, intraoperative blood loss and R0 resection rate. Survival was estimated using the Kaplan-Meier method. The study was conducted according to the Report of the ISPOR Task Force on Retrospective Databases [9]. All procedures were followed in accordance with the ethical standards of the responsible committee on human experimentation (institutional and national) and the Helsinki Declaration of 1975, as revised in 2008. The independent ethics committee of the Jagiellonian University, Krakow (KBET/45/B/2010) approved the study. Informed consent was obtained from all patients before surgery.

During the study period 495 patients were submitted to laparoscopy. In 60/495 (12.1\%) patients a significant suspicion of malignancy was established before surgery through clinical evaluation and diagnostic imaging. In this group, 30 (50 \%) patients were operated due to suspected adrenal metastasis. The malignant character of the tumour was confirmed through pathological examination in 35 (58.3\%) out of the 60 patients. Moreover, in 17 (3.9 \%) more patients, in whom the preoperative imaging did not clearly indicate malignancy, it was confirmed in the postoperative pathological examination. (Table 1). Further analysis included 52 patients with a postoperative diagnosis of malignancy or potential malignancy. This group included 23 women and 29 men. The mean age in the studied group was 57 years (with a range of 19-87 years). The demographic characteristics of this group are presented in Table 2 . 
Table 1 Preoperative and postoperative character of the removed adrenal tumours

\begin{tabular}{lll}
\hline $\begin{array}{l}\text { Preoperative tumour with } \\
\text { suspected malignancy } n=60\end{array}$ & $\begin{array}{l}\text { Postoperative } \\
\text { benign tumour }\end{array}$ & $n=25(41.7 \%)$ \\
& $\begin{array}{l}\text { Postoperative } \\
\text { malignant tumour }\end{array}$ & $n=35(58.3 \%)$ \\
& $\begin{array}{l}\text { Postoperative } \\
\text { Preoperative tumour without } \\
\text { suspicion of malignancy } n=435\end{array}$ & $n=17(3.9 \%)$ \\
& $\begin{array}{l}\text { malignant tumour } \\
\text { Postoperative } \\
\text { benign tumour }\end{array}$ & $n=418(96.1 \%)$ \\
\hline
\end{tabular}

Fourteen (26.9\%) patients had a primary malignant adrenal tumour, 22 (42.3\%) adrenal metastasis and in 16 (30.8\%) pheochromocytoma with the malignant phenotype. Out of 14 primary malignant lesions, 3 (21.4 \%) were hormonally active ( $2 \mathrm{x}$ glucocorticoid-secreting and 1 aldosterone-secreting). None of the metastases were hormonally active, whereas in 15/16 (93.7 \%) cases of pheochromocytoma, catecholamines hypersecretion was confirmed preoperatively. Table 3 presents the pathological types of the removed lesions.

\section{Results}

In $47(90.3 \%)$ of the patients, the tumour was removed using the laparoscopic technique. Conversion was necessary in $5(9.7 \%)$ of the patients. The reasons for conversion are presented in Table 4.

Mean blood loss was $220 \mathrm{ml}(10-1500 \mathrm{ml})$. In 3 patients blood transfusions were necessary. Complications occurred in a total of 6 patients $(11.5 \%)$ and included hepatic parenchymal injury, damage to the splenic vein (not requiring splenectomy), aortic injury (during the open phase after conversion), pleural effusion and surgical site infection in 2 patients. None of the patients required reoperation. One female patient with multiple co-morbidities (ASA IV) with a pheochromocytoma that was additionally secreting corticosteroids required transfer to the intensive care unit on the day of surgery due to cardiopulmonary decompensation. This patient died on the $6^{\text {th }}$ postoperative day.

Pathologic results confirmed R0 resection in 41 (78.8\%) of the patients and R1 resection in 9 (17.3\%) of the patients. In 2 (3.9\%) of the patients $\mathrm{R} 2$ resection was performed. Postoperative mitotane therapy was applied in all patients with ACC and in 8 patients with

Table 2 Demographic characteristics of the study group

\begin{tabular}{ll}
\hline Number of patients & 52 \\
Number of women & $23(44.2 \%)$ \\
Number of men & $29(55.8 \%)$ \\
Mean age & 57 years (19-87 years) \\
Mean tumour size & $58 \mathrm{~mm}(18-160 \mathrm{~mm})$ \\
Left/right side & $21 / 31$ \\
\hline
\end{tabular}

metastasis, adjuvant chemotherapy was introduced according to the type of cancer. Patients with pheochromocytoma were not subject to adjuvant treatment. The mean follow-up time was 32.9 months (median: 24 months). One patient who died in the hospital was excluded from the analysis of follow-up time and longterm survival. The Kaplan-Meier survival curves for the entire group as well as for each tumour type are presented in Figs. 1 and 2.

\section{Discussion}

According to most, if not all guidelines, any suspected adrenal malignancy is an indication for open adrenalectomy and this recommendation is very rarely questioned $[10,11]$. Nowadays, most adrenalectomies worldwide are performed laparoscopically. Analyzing indications it becomes obvious that, at least in some cases, the abovementioned rule is silently and unnoticeably violated. Indeed, the true indication for the removal of incidentalomas results from concern that the early stages of cancer may have been overlooked [12]. All guidelines raise the issue of selection of cases where the risk of malignancy is high enough to justify adrenalectomy in hormonally silent tumours. As a natural consequence the firm adherence to this principle "always open surgery in any suspicion of malignant tumour" automatically implies that all incidentalomas should be operated classically. Meanwhile, looking at most series of minimally invasive adrenalectomy, at least half of all patients operated on for incidentalomas and internal contradiction using this approach is never questioned [13-15]. Thus, we believe that the opinion about open surgery for nonsecreting tumours should be revised. In our series the risk of malignancy in unsuspected incidentalomas was $3.9 \%$. Similar data can be found elsewhere $[15,16]$. This implies that removing every incidentaloma in this way would be unnecessary overtreatment in almost all cases.

Even though it may sound controversial, we believe that the same is true for cases with a higher risk of malignancy. The precise preoperative diagnostics of the potentially malignant character of pheochromocytomas remains an important challenge. It is generally accepted that in over $10 \%$ of cases they can exhibit a malignant phenotype [17]. Only metastases observed at diagnosis or infiltration of surrounding organs observed at diagnosis are certain features of malignancy. This is, however, very rare. In most cases, they develop postoperatively in the follow-up period. Unfortunately, if there are no metastases, it is not possible to precisely evaluate the degree of malignancy based on biochemical and imaging tests $[18,19]$. Pathological examination may also prove inconclusive. The most frequently employed scale for estimating the risk is PASS (Pheochromocytoma of the Adrenal Gland Scaled Score), proposed by Thompson in 2002 [20]. Though 
Table 3 Pathological types of the removed lesions

\begin{tabular}{|c|c|c|c|c|}
\hline & Mean size & Histological type & $n(\%)$ & $n(\%)$ \\
\hline \multirow[t]{3}{*}{ Primary malignant adrenal tumour } & 74.9 mm (23 - $160 \mathrm{~mm})$ & Adrenocortical cancer (ACC) & $12(23.1 \%)$ & $14(26.9 \%)$ \\
\hline & & Primitive neuroectodermal tumour (PNET) & $1(1.9 \%)$ & \\
\hline & & Lymphoma & $1(1.9 \%)$ & \\
\hline \multirow[t]{5}{*}{ Metastasis } & 46.9 mm (18-80 mm) & Renal cell carcinoma & $11(21.2 \%)$ & $22(42.3 \%)$ \\
\hline & & Non-small cell lung cancer & $7(13.5 \%)$ & \\
\hline & & Colonic adenocarcinoma & $2(3.8 \%)$ & \\
\hline & & Hepatocellular carcinoma & $1(1.9 \%)$ & \\
\hline & & Sarcoma & $1(1.9 \%)$ & \\
\hline Malignant pheochromocytoma & $59.8 \mathrm{~mm}(23-120 \mathrm{~mm})$ & Malignant pheochromocytoma (PASS $\geq 6$ ) & $16(30.8 \%)$ & $16(30.8 \%)$ \\
\hline All & $58 \mathrm{~mm}(18-160 \mathrm{~mm})$ & & $52(100 \%)$ & $52(100 \%)$ \\
\hline
\end{tabular}

highly popular, its effectiveness for discovering malignant pheochromocytomas is highly debatable [21, 22]. Thompson has suggested that tumours with a PASS $\geq 6$ were biologically more aggressive than tumours with a PASS $<4$. Meanwhile, Strong has observed that all patients in whom a progression of the disease was observed had tumours with a PASS over 6 [8]. This criterion was adapted for the purposes of our analysis. However, based on our observations, it appears that if there are no metastases during the operation, the risk of relapse is very low, since none of our patients relapsed. To some extent, this confirms the opinions that the PASS, despite being the most frequently used tool, does not allow for precisely predicting the postoperative course after the adrenalectomy for pheochromocytoma. An important conclusion arising from the analysis of our results is that laparoscopic adrenalectomy is a safe procedure in cases of pheochromocytoma considered as potentially malignant neoplasms. Additionally, if the pathological examination shows characteristics that may indicate a malignant phenotype, the procedure does not have a negative impact on the patient's outcomes, as compared to open surgery. Other authors also consider laparoscopic surgery a safe method, and recommend it as the method of choice, regardless of tumour size and the preoperative clinical picture, even though the malignant potential of pheochromocytoma is relatively high [23-25].

Table 4 Reasons for conversion

\begin{tabular}{lll}
\hline Final diagnosis & Size $(\mathrm{mm})$ & Reason of conversion \\
\hline Pheochromocytoma & 50 & $\begin{array}{l}\text { Infiltration to the back wall of the } \\
\text { abdominal cavity }\end{array}$ \\
$\begin{array}{l}\text { ACC } \\
\begin{array}{l}\text { Metastasis } \\
\text { (renal cell cancer) }\end{array}\end{array} \quad 88$ & $\begin{array}{l}\text { Suspicion of tumour capsule injury } \\
\text { Adhesions after a previous surgery }\end{array}$ \\
ACC & 120 & $\begin{array}{l}\text { Impossibility of safe laparoscopic } \\
\text { dissection }\end{array}$ \\
Pheochromocytoma & 120 & uncontrolled bleeding \\
\hline
\end{tabular}

Nowadays, laparoscopic surgery has become a good alternative to open surgery in patients with isolated metastases. Despite certain controversy surrounding attempts at surgical treatment in patients with advanced stage cancer, it seems that, taking into account the advantages of minimally invasive techniques, laparoscopic adrenalectomy is perceived as an effective treatment method in chosen cases [26-28]. Research including relatively numerous groups of patients shows that such treatment enables prolonged disease free survival. In Moreno's study of 317 patients, the survival rate after one, two, three and five years was $80 \%, 61 \%, 42 \%$ and $35 \%$, respectively [26]. Romero Arenas reported similar results (70\% survival after a year, $44 \%$ after 3 years and $38 \%$ after 5 years) [27]. Vazquez underlined one more important aspect - the treatment results depend also on the type of the primary tumour and thus may differ between study groups [29]. In our study, the survival rates for patients with metastases after a year, 2 years and 5 years were $82.4 \%, 46.2 \%$ and $40 \%$, respectively, which is similar to the results reported by other authors. The published papers comparing laparoscopic adrenalectomy with open surgery did not indicate any difference in survival rate between the methods, though they did note the obvious advantages of laparoscopy in early postoperative outcomes. All this contributes to a preference for laparoscopy in patients with metastases to the adrenal glands [30, 31, 26, 32-35, 29].

Our approach favours laparoscopy in all adrenal gland tumours, as it clearly emerges from this paper. In our series, in only $67.3 \%(35 / 52)$ of the adrenal tumours with histologically confirmed malignant character was there significant suspicion of malignancy preoperatively. Furthermore, out of this group, $85.7 \%$ (30/35) were patients with metastases. In other cases $(17,32.6 \%)$ the character of the malignant or potentially malignant tumour was determined only postoperatively. Such a context calls into question the legitimacy of recommendations, which favour open techniques in these cases as 


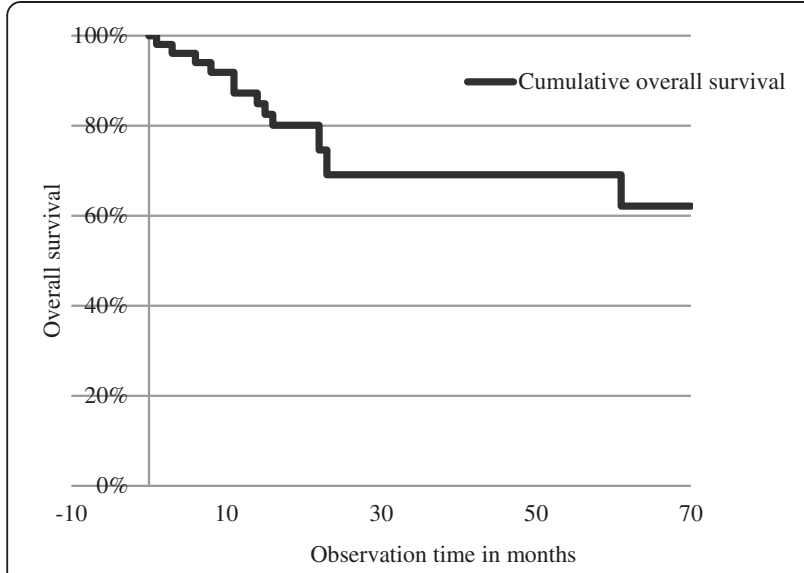

Fig. 1 Kaplan-Meier survival curve for the entire group

nearly $1 / 3$ of malignant tumours would be operated laparoscopically anyway. Some authors argue that in the case of primary adrenal malignancy, the preferred technique should be open surgery. They argue that local recurrence and peritoneal metastases occur sooner in patients who undergo laparoscopic adrenalectomy and positive resection margins are more frequently positive [36-39]. Others believe that the surgical approach does not have such a significant impact [7, 40,41]. It seems that the role of the operative technique is the key question in this debate. In our opinion, laparoscopy differs only in that it involves a different access to the operated area. It allows for performing exactly the same operation meeting all the oncological principles (including in multi-organ resection and full lymphadenectomy) as long as it is performed by a skilled and experienced surgeon. We are certain that this aspect has more influence on the outcomes than the type of access itself. Moreover, in tumours located elsewhere (for instance, colon cancer), laparoscopy is an equal alternative to open operations, while giving the well-known advantages of reduced surgical trauma [42,43]. It is even more so from a practical point of view, since a return to more frequent application of open surgery seems impossible, and often stands in contradiction to the expectations of both the patients and surgeons. It seems, however, reasonable that beginning every operation with laparoscopy, even in cases of larger and potentially malignant tumours, may be beneficial. It allows for a minimally invasive assessment of the entire abdominal cavity, searching for distant metastases and estimating the possibility of radical resection of the lesion without exposing the patient to large surgical trauma. Obviously the need for conversion arises whenever technical difficulties put into question the oncological quality of the procedure (dissecting the tumour, which could lead to damaging the tumour capsule, or doubts as to possible infiltration of neighbouring organs) $[44,5,45,11]$. We also do not support laparoscopic surgery at all costs. Overall, conversion was necessary for 5 patients, out of which in 3 cases it was for "oncological reasons" (impossibility of dissecting the tumour, suspicion of capsule rupture). In the remaining $47(90.3 \%)$ patients, the procedure was carried out laparoscopically. The presented R0 resection rate of $78.8 \%$ is a fully acceptable result, and certainly comparable, if not better than the results for open surgery $[7,36,39]$. This suggests that the laparoscopy allows for the achievement of satisfactory oncological outcomes. According to our data, the survival rate for patients with ACC after 1,2 , and 5 years was, respectively, $81.8 \%, 70 \%$ and $50 \%$. These results are slightly better than in other papers; however, they need to be interpreted with some caution, given the small study group size [46, 6]. Another issue is that we are the high-volume referral centre for adrenal pathologies and this is a proven factor for better outcomes $[47,48]$.

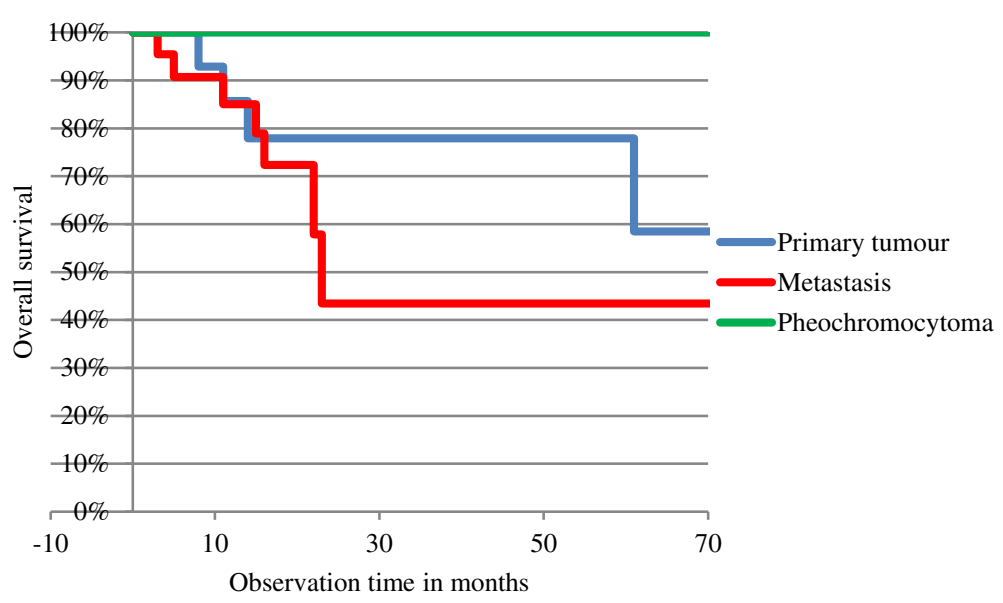

Fig. 2 Kaplan-Meier survival curves for each tumor type 
Our study is not free from limitations. It is a single centre retrospective study on a small sample, therefore defining confounders can be difficult and there is a potential for population bias. All procedures were performed by the same very experienced laparoscopic surgeon (>370 laparoscopic adrenalectomies), therefore the results probably cannot be simply transferred to all surgical departments.

\section{Conclusions}

In summary, we consider that laparoscopic surgery for malignant or potentially malignant adrenal tumours is feasible. Safe laparoscopic surgery for any type of pheochromocytoma is a fact; especially that we are not able to distinguish a malignant from a benign tumour and even if it turns out to be potentially malignant, the longterm survival is very good. In patients with metastatic malignancy, adrenal metastasectomy seems to be a reasonable, less invasive solution allowing for comparable if not better results. Finally, the biggest concern remains primary adrenocortical cancer. Our results suggest that it is impossible to predict its occurrence in incidentalomas. In our opinion, if laparoscopy does not improve the outcomes, in the hand of an experienced surgeon it guarantees the possibility of noninferiority. Therefore, it can be recommended in most tumours. Additionally, beginning a procedure with laparoscopy allows for a precise, minimally invasive evaluation of the tumour stage. The key element in surgery for any suspected malignancy is not the surgical access itself but the proper technique in accordance with the principles of oncological surgery.

\section{Abbreviations \\ CT: Computed tomography; MRI: Magnetic resonance imaging; PET: Positron emission tomography scan; ACTH: Adrenocorticotropic hormone; DHEAS: Dehydroepiandrosterone sulphate; ACC: Adrenocortical cancer; PASS: Pheochromocytoma of Adrenal Gland Scaled Score; ASA: American Society of Anesthesiologists physical status.}

\section{Competing interests}

The authors have no competing interests to declare.

\section{Authors' contributions}

MP carried out the analysis and interpretation of data, participated in the conception and design of the work, and drafted the article. MW participated in the acquisition and interpretation of data and critically revised the manuscript. MN, MM, MB, PM participated in the acquisition and interpretation of data as well as patients management. PB participated in the analysis and interpretation of data and patients follow-up. AHD participated in data collection, patients management and follow-up. AB performed most of surgeries and participated in the conception and design of the study, he also revised the manuscript. All authors read and approved the final manuscript.

\section{Authors' information}

MP - MD, PhD - laparoscopic surgeon, interested in adrenal and colorectal surgery, Enhanced Recovery After Surgery Program coordinator in his Department.

MW - MD - surgeon and physiologist, writing his PhD thesis on pathophysiology of adrenals.
MM - MD, PhD - laparoscopic surgeon, involved in bariatric surgery as well as research on perioperative metabolic stress.

$M B-M D, P h D$, pathologist - an expert in histopathology of adrenals.

$M N$ - MD, surgeon, statistician.

PM - MD, PhD - laparoscopic surgeon.

$\mathrm{PB}-\mathrm{MD}, \mathrm{PhD}$ - endocrine surgeon.

AHD - Prof., Head of the Department of Endocrinology, Especially interested in adrenal tumors and neuroendocrine disorders.

AB - Prof., Head of the Department of Surgery, laparoscopic surgeon with enormous expertise in laparoscopy. He has performed more than 370 adrenalectomies. He is also an expert in laparoscopic surgery of the stomach, colon, rectum and the spleen. He was first to perform laparoscopic total pancreatoduodenectomy and laparoscopic hemihepatectomy in our country. An outstanding teacher.

\section{Acknowledgements}

The publication of this paper was supported by the Faculty of Medicine, Jagiellonian University Medical College, Leading National Research Centre (KNOW) 2012-2017.

\section{Author details}

'2nd Department of General Surgery, Jagiellonian University, Kopernika 21, 31-501 Kraków, Poland. 'Department of Physiology, Jagiellonian University, Grzegórzecka 16, 31-531 Kraków, Poland. ${ }^{3}$ Department of Pathology, Jagiellonian University, Grzegórzecka 16, 31-531 Kraków, Poland. ${ }^{4}$ Department of Endocrinology, Jagiellonian University, Kopernika 17, 31-531 Kraków, Poland.

Received: 7 January 2015 Accepted: 21 August 2015

Published online: 28 August 2015

\section{References}

1. Gumbs AA, Gagner M. Laparoscopic adrenalectomy. Best Pract Res Clin Endocrinol Metab. 2006;20(3):483-99. doi:10.1016/j.beem.2006.07.010.

2. Smith CD, Weber CJ, Amerson JR. Laparoscopic adrenalectomy: new gold standard. World J Surg. 1999;23(4):389-96.

3. Allolio B. Is endoscopic adrenalectomy the treatment of choice for large primary adrenal tumors? Nat Clin Pract Endocrinol Metab. 2006;2(1):16-7. doi:10.1038/ncpendmet0070.

4. Asari $\mathrm{R}$, Koperek $\mathrm{O}$, Niederle B. Endoscopic adrenalectomy in large adrenal tumors. Surgery. 2012;152(1):41-9. doi:10.1016/j.surg.2012.02.003.

5. Henry JF, Sebag F, lacobone M, Mirallie E. Results of laparoscopic adrenalectomy for large and potentially malignant tumors. World J Surg. 2002;26(8):1043-7. doi:10.1007/s00268-002-6666-0.

6. Lombardi CP, Raffaelli M, De Crea C, Bellantone R. Role of laparoscopy in the management of adrenal malignancies. J Surg Oncol. 2006;94(2):128-31. doi:10.1002/jso.20599.

7. Brix D, Allolio B, Fenske W, Agha A, Dralle H, Jurowich C, et al. Laparoscopic versus open adrenalectomy for adrenocortical carcinoma: surgical and oncologic outcome in 152 patients. Eur Urol. 2010;58(4):609-15. doi:10.1016/j.eururo.2010.06.024.

8. Strong VE, Kennedy T, Al-Ahmadie H, Tang L, Coleman J, Fong Y, et al. Prognostic indicators of malignancy in adrenal pheochromocytomas: clinical, histopathologic, and cell cycle/apoptosis gene expression analysis. Surgery. 2008;143(6):759-68. doi:10.1016/j.surg.2008.02.007.

9. Motheral B, Brooks J, Clark MA, Crown WH, Davey P, Hutchins D, et al. A checklist for retrospective database studies-report of the ISPOR Task Force on Retrospective Databases. Value Health. 2003;6(2):90-7. doi:10.1046/j.1524-4733.2003.00242.x.

10. Berruti A, Baudin E, Gelderblom H, Haak HR, Porpiglia F, Fassnacht M, et al. Adrenal cancer: ESMO Clinical Practice Guidelines for diagnosis, treatment and follow-up. Ann Oncol. 2012;23(7):vii131-8. doi:10.1093/annonc/mds231.

11. Stefanidis D, Goldfarb M, Kercher KW, Hope WW, Richardson W, Fanelli RD. SAGES guidelines for minimally invasive treatment of adrenal pathology. Surg Endosc. 2013;27(11):3960-80. doi:10.1007/s00464-013-3169-z.

12. Pedziwiatr M, Natkaniec M, Kisialeuski M, Major P, Matlok M, Kolodziej D, et al. Adrenal incidentalomas: should we operate on small tumors in the era of laparoscopy? Int j endocrinol. 2014;2014:658483. doi:10.1155/2014/658483. 
13. Kulis T, Knezevic N, Pekez M, Kastelan D, Grkovic M, Kastelan Z. Laparoscopic adrenalectomy: lessons learned from 306 cases. J Laparoendosc Adv Surg Tech A. 2012;22(1):22-6. doi:10.1089/lap.2011.0376.

14. Musella M, Conzo G, Milone M, Corcione F, Belli G, De Palma M, et al. Preoperative workup in the assessment of adrenal incidentalomas: outcome from 282 consecutive laparoscopic adrenalectomies. BMC Surg. 2013;13:57. doi:10.1186/1471-2482-13-57.

15. Conzo G, Tricarico A, Belli G, Candela S, Corcione F, Del Genio G, et al. Adrenal incidentalomas in the laparoscopic era and the role of correct surgical indications: observations from 255 consecutive adrenalectomies in an Italian series. Canadian journal of surgery Journal canadien de chirurgie. 2009;52(6):E281-5

16. Mansmann G, Lau J, Balk E, Rothberg M, Miyachi Y, Bornstein SR. The clinically inapparent adrenal mass: update in diagnosis and management. Endocr Rev. 2004;25(2):309-40. doi:10.1210/er.2002-0031.

17. Elder EE, Elder G, Larsson C. Pheochromocytoma and functional paraganglioma syndrome: no longer the $10 \%$ tumor. J Surg Oncol. 2005;89(3):193-201. doi:10.1002/jso.20177.

18. Bravo EL, Tagle R. Pheochromocytoma: state-of-the-art and future prospects. Endocr Rev. 2003;24(4):539-53. doi:10.1210/er.2002-0013.

19. Chrisoulidou A, Kaltsas G, Ilias I, Grossman AB. The diagnosis and management of malignant phaeochromocytoma and paraganglioma. Endocr Relat Cancer. 2007;14(3):569-85. doi:10.1677/ERC-07-0074.

20. Thompson LD. Pheochromocytoma of the Adrenal gland Scaled Score (PASS) to separate benign from malignant neoplasms: a clinicopathologic and immunophenotypic study of 100 cases. Am J Surg Pathol. 2002;26(5):551-66.

21. Agarwal A, Mehrotra PK, Jain M, Gupta SK, Mishra A, Chand G, et al. Size of the tumor and pheochromocytoma of the adrenal gland scaled score (PASS): can they predict malignancy? World J Surg. 2010;34(12):3022-8. doi:10.1007/s00268-010-0744-5.

22. de Wailly P, Oragano L, Rade F, Beaulieu A, Arnault V, Levillain P, et al. Malignant pheochromocytoma: new malignancy criteria. Langenbecks Arch Surg. 2012;397(2):239-46. doi:10.1007/s00423-011-0850-3.

23. Conzo G, Musella M, Corcione F, De Palma M, Ferraro F, Palazzo A, et al. Laparoscopic adrenalectomy, a safe procedure for pheochromocytoma. A retrospective review of clinical series. Int J Surg. 2013;11(2):152-6. doi:10.1016/j.jijsu.2012.12.007.

24. Liao CH, Chueh SC, Lai MK, Hsiao PJ, Chen J. Laparoscopic adrenalectomy for potentially malignant adrenal tumors greater than 5 centimeters. J Clin Endocrinol Metab. 2006;91(8):3080-3. doi:10.1210/jc.2005-2420.

25. Hobart MG, Gill IS, Schweizer D, Sung GT, Bravo EL. Laparoscopic adrenalectomy for large-volume (> or $=5 \mathrm{~cm}$ ) adrenal masses. J Endourol. 2000;14(2):149-54.

26. Moreno P, de la Quintana BA, Musholt TJ, Paunovic I, Puccini M, Vidal O, et al. Adrenalectomy for solid tumor metastases: results of a multicenter European study. Surgery. 2013;154(6):1215-22. doi:10.1016/j.surg.2013.06.021. discussion 22-3.

27. Romero Arenas MA, Sui D, Grubbs EG, Lee JE, Perrier ND. Adrenal metastectomy is safe in selected patients. World J Surg. 2014;38(6):1336-42. doi:10.1007/s00268-014-2454-x.

28. Sancho JJ, Triponez F, Montet X, Sitges-Serra A. Surgical management of adrenal metastases. Langenbecks Arch Surg. 2012;397(2):179-94. doi:10.1007/s00423-011-0889-1.

29. Vazquez BJ, Richards ML, Lohse CM, Thompson GB, Farley DR, Grant CS, et al. Adrenalectomy improves outcomes of selected patients with metastatic carcinoma. World J Surg. 2012;36(6):1400-5. doi:10.1007/s00268-012-1506-3.

30. Adler JT, Mack E, Chen H. Equal oncologic results for laparoscopic and open resection of adrenal metastases. J Surg Res. 2007;140(2):159-64. doi:10.1016/j.jss.2006.08.035

31. Bradley CT, Strong VE. Surgical management of adrenal metastases. J Surg Oncol. 2014;109(1):31-5. doi:10.1002/jso.23461.

32. Sarela Al, Murphy I, Coit DG, Conlon KC. Metastasis to the adrenal gland: the emerging role of laparoscopic surgery. Ann Surg Oncol. 2003;10(10):1191-6.

33. Sebag F, Calzolari F, Harding J, Sierra M, Palazzo FF, Henry JF. Isolated adrenal metastasis: the role of laparoscopic surgery. World J Surg. 2006:30(5):888-92. doi:10.1007/s00268-005-0342-0.

34. Strong VE, D'Angelica M, Tang L, Prete F, Gonen M, Coit D, et al. Laparoscopic adrenalectomy for isolated adrenal metastasis. Ann Surg Oncol. 2007:14(12):3392-400. doi:10.1245/s10434-007-9520-7.
35. Valeri A, Bergamini C, Tozzi F, Martellucci J, Di Costanzo F, Antonuzzo L. A multi-center study on the surgical management of metastatic disease to adrenal glands. J Surg Oncol. 2011;103(5):400-5. doi:10.1002/jso.21843.

36. Cooper AB, Habra MA, Grubbs EG, Bednarski BK, Ying AK, Perrier ND, et al. Does laparoscopic adrenalectomy jeopardize oncologic outcomes for patients with adrenocortical carcinoma? Surg Endosc. 2013;27(11):4026-32. doi:10.1007/s00464-013-3034-0.

37. Gonzalez RJ, Shapiro S, Sarlis N, Vassilopoulou-Sellin R, Perrier ND, Evans DB, et al. Laparoscopic resection of adrenal cortical carcinoma: a cautionary note. Surgery. 2005;138(6):1078-85. doi:10.1016/j.surg.2005.09.012. discussion 85-6.

38. Leboulleux S, Deandreis D, Al Ghuzlan A, Auperin A, Goere D, Dromain C, et al. Adrenocortical carcinoma: is the surgical approach a risk factor of peritoneal carcinomatosis? Eur J Endocrinol. 2010;162(6):1147-53. doi:10.1530/EJE-09-1096.

39. Miller BS, Ammori JB, Gauger PG, Broome JT, Hammer GD, Doherty GM. Laparoscopic resection is inappropriate in patients with known or suspected adrenocortical carcinoma. World J Surg. 2010;34(6):1380-5. doi:10.1007/s00268-010-0532-2.

40. Nocca D, Aggarwal R, Mathieu A, Blanc PM, Deneve E, Salsano V, et al. Laparoscopic surgery and corticoadrenalomas. Surg Endosc. 2007:21(8):1373-6. doi:10.1007/s00464-007-9218-8.

41. Porpiglia F, Fiori C, Daffara F, Zaggia B, Bollito E, Volante M, et al. Retrospective evaluation of the outcome of open versus laparoscopic adrenalectomy for stage I and II adrenocortical cancer. Eur Urol. 2010;57(5):873-8. doi:10.1016/j.eururo.2010.01.036.

42. Jayne DG, Thorpe HC, Copeland J, Quirke P, Brown JM, Guillou PJ. Five-year follow-up of the Medical Research Council CLASICC trial of laparoscopically assisted versus open surgery for colorectal cancer. Br J Surg. 2010;97(11):1638-45. doi:10.1002/bjs.7160.

43. Trastulli S, Cirocchi R, Listorti C, Cavaliere D, Avenia N, Gulla N, et al. Laparoscopic vs open resection for rectal cancer: a meta-analysis of randomized clinical trials. Colorectal Dis. 2012;14(6):e277-96. doi:10.1111/ j.1463-1318.2012.02985.x

44. Henry JF, Defechereux T, Raffaelli M, Lubrano D, Gramatica L. Complications of laparoscopic adrenalectomy: results of 169 consecutive procedures. World J Surg. 2000;24(11):1342-6.

45. Shen WT, Sturgeon C, Duh QY. From incidentaloma to adrenocortical carcinoma: the surgical management of adrenal tumors. J Surg Oncol. 2005;89(3):186-92. doi:10.1002/jso.20180.

46. Janetschek G. Surgical options in adrenalectomy: laparoscopic versus open surgery. Curr Opin Urol. 1999;9(3):213-8.

47. Lombardi CP, Raffaelli M, Boniardi M, De Toma G, Marzano LA, Miccoli P, et al. Adrenocortical carcinoma: effect of hospital volume on patient outcome. Langenbecks Arch Surg. 2012;397(2):201-7. doi:10.1007/s00423-011-0866-8.

48. Lachenmayer A, Cupisti K, Wolf A, Raffel A, Schott M, Willenberg HS, et al. Trends in adrenal surgery: institutional review of 528 consecutive adrenalectomies. Langenbecks Arch Surg. 2012;397(7):1099-107. doi:10.1007/s00423-012-0973-1.

\section{Submit your next manuscript to BioMed Central and take full advantage of:}

- Convenient online submission

- Thorough peer review

- No space constraints or color figure charges

- Immediate publication on acceptance

- Inclusion in PubMed, CAS, Scopus and Google Scholar

- Research which is freely available for redistribution 